\title{
Field Emission Properties of Single-Walled Carbon Nanotubes with a
}

\section{Variety of Emitter-Morphologies}

Yosuke SHIRATORI*, Koji FURUICHI ${ }^{1}$, Suguru NODA ${ }^{* *}$, Hisashi SUGIME, Yoshiko TSUJI, Zhengyi ZHANG ${ }^{2}$, Shigeo MARUYAMA ${ }^{2}$, and Yukio YAMAGUCHI

Department of Chemical System Engineering, School of Engineering, The University of Tokyo, 7-3-1 Hongo, Bunkyo-ku, Tokyo 113-8656, Japan

${ }^{1}$ DAINIPPON SCREEN MFG. CO., LTD., Tenjinkita 1-1, Teranouchi-agaru 4, Horikawa-dori, Kamigyo-ku, Kyoto 602-8585, Japan

${ }^{2}$ Department of Mechanical Engineering, School of Engineering, The University of Tokyo, 7-3-1 Hongo, Bunkyo-ku, Tokyo 113-8656, Japan

*E-mail address: y-shiratori@chemsys.t.u-tokyo.ac.jp

**E-mail address: noda@chemsys.t.u-tokyo.ac.jp

Field emission properties of single-walled carbon nanotubes (SWNTs), which have been prepared through alcohol catalytic chemical vapor deposition for $10-60 \mathrm{~s}$, were characterized in a diode configuration. Protrusive bundles at the top surface of samples act selectively as emission sites. The number of emission sites was controlled by emitter morphologies combined with texturing of Si substrates. SWNTs grown on a textured Si 
substrate exhibited a turn-on field as low as $2.4 \mathrm{~V} / \mu \mathrm{m}$ at a field emission current density of $1 \mu \mathrm{A} / \mathrm{cm}^{2}$. Uniform spatial luminescence $\left(0.5 \mathrm{~cm}^{2}\right)$ from the rear surface of the anode was revealed for SWNTs prepared on the textured Si substrate. Deterioration of field emission properties through repetitive measurements was reduced for the textured samples in comparison with vertically aligned SWNTs and a random network of SWNTs prepared on flat Si substrates. Emitter morphology resulting in improved field emission properties is a crucial factor for the fabrication of SWNT-electron sources. Morphologically controlled SWNTs with promising emitter performances are expected to be practical electron sources.

KEYWORDS: single-walled carbon nanotube, field emission, alcohol catalytic chemical vapor deposition, ethanol, textured $\mathrm{Si}$, Raman spectroscopy 


\section{Introduction}

Since the potential of carbon nanotubes (CNTs) as electron sources was demonstrated by Rinzler et al., ${ }^{1)}$ much effort has been devoted to trial applications of CNTs for field emission displays (FEDs). Several different types of CNTs have been implemented into triode-type FEDs. The Samsung and the Motorola groups reported potential of color-SWNT- and -MWNT-FEDs, ${ }^{2,3)}$ respectively. However the practical performance requirements for CNT-FEDs, e.g. uniformity of emission sites and high extractive ratio (anode current/cathode current) in a triode-configuration, have not achieved levels comparable to the Spindt-type FED. ${ }^{4)}$ Due to their large tip-curvature and metallic conductivity, excellent field emission properties of CNTs have been demonstrated by numerous groups, however their practical use has not yet been realized.

One of the major obstacles to developing CNT-FEDs is the severe conditions, such as high-temperatures required for growth especially for SWNTs. For the cases of low-temperature plasma-enhanced chemical vapor deposition (CVD), ambitious infrastructure is necessary. For the CNT-FED equipped with screen-printed SWNT-emitters, ${ }^{2)}$ which were fabricated under mild conditions, large cathode-holes result in a reduced hole density compared with the Spindt-type FED, causing an 
inhomogeneous current distribution.

The choice of CNTs, suitable as electron emitters, is important. SWNTs typically have diameters ranging from 1 to $2 \mathrm{~nm}$, which enhance an applied electric field. On the other hand they consist of only one rolled graphene sheet and they are therefore more flexible than multi-walled nanotubes (MWNTs). We failed to find any literature reporting the accurate sustainable current per SWNT, however their current-durability is believed to be poorer than those for double-walled carbon nanotubes (DWNTs) and MWNTs. This indicates that the ideal concepts of "sustainable emission by thick tubes" and "low extraction voltage by sharp tip" are not mutually achievable.

A number of issues are important for future CNT-FED development. (I) A low-temperature and/or short-time growth directly on cathodes through simple and safe processes, (II) a giant tip-enhancement of an applied field and (III) a uniform spacial current distribution, that is, a large number density of emission sites resulting in a mild current per emitter. We focus here on SWNT-emitters prepared using alcohol catalytic CVD (ACCVD).

ACCVD, which facilitates a low-temperature synthesis (down to $550{ }^{\circ} \mathrm{C}$ ) of high quality SWNTs through a safe process, was developed by Maruyama et al. ${ }^{5)}$ Ethanol was thermally decomposed over the Fe/Co catalytic mixture embedded in zeolite ${ }^{5)}$ and 
the Co-Mo bimetallic catalytic layer dip-coated from a metal acetate solution. ${ }^{6}$ Field electron emission (FE) from the SWNTs synthesized by ACCVD was first observed for samples prepared on mesoporous- $\mathrm{SiO}_{2}(200 \mathrm{~nm}) / \mathrm{Co}-$ nanoparticles/Au-Ti(300 nm)/Si substrates. ${ }^{7)}$ The properties obtained for the SWNTs (the turn-on field of $4.2 \mathrm{~V} / \mu \mathrm{m}$ at the current density of $10 \mu \mathrm{A} / \mathrm{cm}^{2}$ and the current density of $0.5 \mathrm{~mA} / \mathrm{cm}^{2}$ at $5.8 \mathrm{~V} / \mu \mathrm{m}$ ) are believed to be further improved by controlling the emitter morphology and by optimization of growth conditions. On the other hand, randomly oriented SWNTs, which were synthesized using the $\mathrm{CO}$ disproportionation reaction catalyzed by silica-supported Co-Mo bimetal, showed good FE properties due to significant prevention of field-shielding especially for samples with a smaller CNT-bundle size. For this structure the turn-on field was $0.6 \mathrm{~V} / \mu \mathrm{m}$ and the current density was $1 \mathrm{~mA} / \mathrm{cm}^{2}$ at $1.8 \mathrm{~V} / \mu \mathrm{m} .{ }^{8)}$ This suggests that the control of emitter morphology through optimization of catalytic layers and of growth conditions is crucial for further studies.

ACCVD is suitable for SWNT growth directly and selectively on desired positions. SWNTs synthesized from ethanol, which is catalyzed by self-organized metal nanoparticles prepared by RF-magnetron sputtering of metals of the order of 0.1 nm-average thickness and subsequent reduction, has been actively and systematically studied. ${ }^{9,10)}$ Prior to application of ACCVD for device fabrication, suitable catalyst 
compositions to promote a rapid growth of high quality SWNTs, and the FE properties of the obtained SWNTs must be systematically studied. In this paper we report field emission properties of SWNT-emitters with different morphologies prepared through ACCVD, which is catalyzed by representative catalytic/supporting layers $\left(\mathrm{Co} / \mathrm{Al}_{2} \mathrm{O}_{3}(\mathrm{Al})\right)$ and discuss their potential for FED-applications.

\section{Experimental Methods}

Conventional silicon wafers were used as substrates. After removal of the oxidized layer by hydrofluoric acid, a catalyst supporting layer $\left(\mathrm{Al}_{2} \mathrm{O}_{3}\right.$ or $\left.\mathrm{Al}\right)$ and a Co catalytic layer were deposited on the substrates by using a conventional RF-sputtering system. In addition to the substrates with a flat $\operatorname{Si}(100)$ surface, special substrates with textured surfaces were also prepared by a wet chemical etching in hydrazine hydrate at $80{ }^{\circ} \mathrm{C}$. Because the $\mathrm{Si}(111)$ surface is more resistant to etching by a strong base, Si pyramids with the (111) side faces are formed on the (100) surface. Sample preparation conditions are specified for all samples in Table 1. After taking the substrates out of the sputtering chamber, reduction of the oxidized top-surface and subsequent ACCVD were carried out in the hot-wall ACCVD chamber consisting of a quartz glass tube entirely heated by a furnace. After the reduction process, ACCVD was performed at $785^{\circ} \mathrm{C}$ by introducing 
ethanol at $4 \mathrm{kPa}$ for $10-60 \mathrm{~s}$.

Obtained sample-surfaces were observed by a Hitachi S-4700 field emission scanning electron microscope (SEM). Raman spectroscopy was used to evaluate the quality of CNTs at the molecular level. Raman spectroscopy is very powerful since graphite related materials scatter intense peaks at around $1590 \mathrm{~cm}^{-1}$ originating from the in-plane lattice vibrations (G-band) and another peak at around $1350 \mathrm{~cm}^{-1}$ attributed to lattice defects in graphene sheets (D-band). ${ }^{11)}$ The intensity ratio between both bands (G/D-ratio) is an indicator of the quality of obtained CNTs. Raman spectra were recorded by a CHROMEX 501is spectrometer equipped with an ANDOR Technology DV401-FI CCD system under a backscattering configuration. The samples were excited with an $\mathrm{Ar}^{+}$-laser radiation $(488.0 \mathrm{~nm})$, which was focused on sample surfaces through a SEKI TECHNOTRON optical unit and objectives with a magnification of 50 and a numerical aperture of 0.80 .

FE currents from the obtained CNT-films were measured 8 times at about $1 \times 10^{-5}$ $\mathrm{Pa}$ under a diode configuration. The bottom surface of samples was grounded. An indium-tin-oxide (ITO) glass and $150 \mu \mathrm{m}$-thick glass-slides located above a CNT film were used as an anode and spacers, respectively. Measurement areas were approximately $0.9 \mathrm{~cm}^{2}$. Voltage was swept by a KEITHLEY 2410 high-voltage source 
meter, which is simultaneously an ammeter. Measurements were remote-controlled by the LabTracer2 software and optional interfaces. I-V data were recorded every $30 \mathrm{~ms}$ in a voltage ramp of $200 \mathrm{~V} / \mathrm{s}$ and automatically loaded into an equipped PC. To evaluate the luminescence uniformity, pulsed voltages (5 ms, 1/2-duty) were applied. Phosphor layers on ITO/glass substrates were prepared by screen-printing of $\mathrm{ZnO}: \mathrm{Zn}$ powders.

\section{Results and Discussion}

\subsection{Combinations of catalyst / supporting material / substrate}

CNT growth rate and quality are tunable by varying combinations of catalytic materials - supporting materials - substrates. If an $\mathrm{Al}_{2} \mathrm{O}_{3}$ layer is used as a catalyst supporting layer, a higher growth rate is expected due to efficient incorporation of carbon into catalyst particles via $\mathrm{Al}_{2} \mathrm{O}_{3}$ surfaces. ${ }^{12)}$ However an increased Co-thickness (around $1 \mathrm{~nm}$ ) in comparison with the case of the $\mathrm{Co} / \mathrm{SiO}_{2} / \mathrm{Si}$ system ${ }^{9)}$ is necessary. In fact, a Co layer with a thickness of ca. $0.1 \mathrm{~nm}$ on a $\mathrm{SiO}_{2} / \mathrm{Si}$ substrate transforms into Co nano-particles during annealing and such self-organized particles induce growth of high quality SWNTs. Detail roles of the $\mathrm{Al}_{2} \mathrm{O}_{3}$ supporting layer on CNT-growth will be discussed elsewhere. In the present case, the average Co- and $\mathrm{Al}_{2} \mathrm{O}_{3}$-thicknesses are fixed into 1.2 and $10 \mathrm{~nm}$, respectively, which promote growth of relatively high quality 
CNTs. Here the following points should be noted: (1) discrepancy of growth rates obtained under the same conditions (Table I) may attribute to gaseous hydrodynamics and incubation and so on during ACCVD, which are not severely controlled in this work and (2) the $\mathrm{Al}_{2} \mathrm{O}_{3}$ layer as thin as $10 \mathrm{~nm}$, which has a moderate resistance for microcathode applications, acts not only as a catalyst support but also as a resistive layer for stable FE operations in practical triode devices. In order to evaluate the influence of an $\mathrm{Al}_{2} \mathrm{O}_{3}$ layer on $\mathrm{FE}$ behavior, a representative sample with an $\mathrm{Al}$ layer in place of an $\mathrm{Al}_{2} \mathrm{O}_{3}$ layer was also characterized. The main roles of an $\mathrm{Al}$ layer are also inhibition of Co-diffusion into $\mathrm{Si}$ and decomposition of carbon source gas at the oxidized thin layer, but the layer is conductive.

\subsection{VA-CNTs and CNT-grass}

\subsubsection{Characterization of CNTs}

Vertically aligned (VA)-CNTs were prepared on the $\mathrm{Co} / \mathrm{Al}_{2} \mathrm{O}_{3} / \mathrm{Si}$ (Sample A) and $\mathrm{Co} / \mathrm{Al} / \mathrm{Si}$ (Sample B) substrates. A random network of CNTs (CNT-grass) ${ }^{13)}$ was formed on the $\mathrm{Co} / \mathrm{Al}_{2} \mathrm{O}_{3} / \mathrm{Si}$ substrate (Sample $\mathrm{C}$ ). Growth conditions including thicknesses of catalytic/supporting layers are summarized in Table I with those for the other CNTs introduced in \$3.3. SEM micrographs obtained for VA-CNTs and a CNT-grass 
synthesized by ACCVD are shown in Fig. 1. Surface morphology of the VA-CNTs (Fig. 1(a), right) is grass-like consisted of entangled bundles. On the other hand, in Sample C (Fig. 1(c)), free-standing bundles with heights in $\mu \mathrm{m}$ order are found. Protrusion of specific bundles in as-prepared Sample C is much more pronounced in comparison to the VA-SWNTs (Samples A and B) since the protrusive bundles are not buried in the surrounding SWNT-grass (Fig. 1(c)). In the case of the VA-SWNTs, protrusion of bundles is not so pronounced because they are buried in the thick CNT forest (Fig. 1(a), right).

Figure 2 shows representative Raman spectra recorded for Samples A-C. All spectra clearly show radial breathing modes (RBMs) at the low-wavenumber region, indicating the presence of SWNTs. The major peaks marked by triangles correspond to the RBMs of SWNTs with diameters ranging from 0.8 to $1.4 \mathrm{~nm}$, which are estimated from the relationship, $d=248 / \omega(d$ :diameter, $\omega$ : wavenumber $){ }^{5)}$ The peak at around 180 $\mathrm{cm}^{-1}(\boldsymbol{\nabla})$, which is a polarized band enhanced for VA-SWNTs, ${ }^{14)}$ is clearly intensified for Samples A and B. A sharp peak at around $520 \mathrm{~cm}^{-1}$ apparent in Sample C originates from the Si-Si lattice vibration of the Si substrate. The obtained CNTs reveal sharp and split profiles of the G-band and G/D ratios ranging from 6 to 14, which are reasonable profiles for SWNTs. 


\subsubsection{Field emission properties of VA-SWNTs and SWNT-grass}

The current density $(J)$ - electric field $(E)$ curves and the Fowler-Nordheim $(\mathrm{F}-\mathrm{N})$ plots obtained from the first (red) and third (blue) runs for Samples A-C are shown in Fig. 3. Here $J$ is the current divided by the electrode area. According to the $\mathrm{F}-\mathrm{N}$ theory for electron emission from a metal surface at an applied field $E_{\text {local }}$, the obtained current density $J_{\mathrm{FN}}\left(\mathrm{Acm}^{-2}\right)$ is given by eq. $(1)^{8)}$,

$$
J_{\mathrm{FN}}=\frac{1.54 \times 10^{-6}\left(E_{\text {local }}\right)^{2}}{\phi} \exp \left\{-\frac{6.83 \times 10^{7} \phi^{1.5}}{E_{\text {local }}}\right\},
$$

where $E_{\text {local }}$ is a local field at an emission site given in $\mathrm{Vcm}^{-1}$ and $\phi$ is the work function of an emitter material in $\mathrm{eV}$. Here we assume $\phi$ of the present SWNTs is 5 $\mathrm{eV}^{11)}$ which is a typical value for graphite. The field enhancement factor $\beta$ (in $\mathrm{cm}^{-1}$ ) is defined in terms of $E_{\text {local }}=\beta V$, where $V$ is an applied voltage. Equation (1) is transformed as

$$
\ln \left(I / V^{2}\right)=-\frac{6.83 \times 10^{7} \times \phi^{1.5}}{\beta} \times(1 / V)+\ln \left(\frac{1.54 \times 10^{-6} \times S \beta^{2}}{\phi}\right),
$$

where $S$ is an effective emission area in $\mathrm{cm}^{2}$. Because the coefficient of $1 / V$ and the last term in eq. (2) are uniquely determined for each emitter structure, the relationship between $1 / V$ and $\ln \left(I / V^{2}\right)$ should be linear if an anode current originates from field electron emission. $\beta$ values are estimated from slopes of the relationship. The FE 
parameters obtained for Samples A-C are listed in Table II with those for other samples introduced in $\S 3.3$. The values for the first run and the average values for the subsequent runs are shown separately. The data for the second runs are excluded since they show the mixed properties of the first run and the subsequent runs.

For the first runs (Fig. 3(a), red), the turn-on fields $\left(E_{\mathrm{to}}\right)$, which extract the current density of $1 \mu \mathrm{A} / \mathrm{cm}^{2}$, and the current densities at $4 \mathrm{~V} / \mu \mathrm{m}\left(J_{4.0}\right)$ are smaller and larger than those from the subsequent runs (Fig. 3(a), bule), respectively. Large field enhancement occurs during the first run. The $\beta$ values calculated from the slopes $\left(\mathrm{s}_{1}\right.$ and $\mathrm{s}_{2}$ in Fig. 3(b)) are listed in Table II; lines 1, 3 and 5. Subsequent runs reveal almost linear F-N plots (shown in blue) and deterioration of FE characteristics (Table II; lines 2, 4 and 6). Samples A (open circle) and B (closed circle) showed similar FE characteristics (Fig. 3, Table II), indicating that we can exclude difference of supporting layers $\left(\mathrm{Al}_{2} \mathrm{O}_{3}\right.$ or $\left.\mathrm{Al}\right)$ from the major factors determining FE properties. The first run $\mathrm{F}-\mathrm{N}$ characteristic is especially non-linear and comprises two types of relationships (Fig. 3(b)). Possible factors contributing to the non-linearity are (1) adsorbate-enhanced field emission, ${ }^{15-17)}$ (2) current-induced evaporation (Joule heating), ${ }^{17-20)}$ (3) stretching of entangled CNTs ${ }^{18,21)}$ or "Y" shape splitting of a bundle during voltage sweep, ${ }^{18)}$ (4) a local density of states (LDOS) at the tips of CNTs, ${ }^{22-24)}$ (5) effect of space charge caused 
by ionization of residual gases, ${ }^{21,23-26)}$ and (6) a large resistance between CNTs and a cathode electrode. ${ }^{17)}$ In the present case, the resistance between SWNTs and the backside of a Si substrate is several to several tens of $\mathrm{k} \Omega$. Since the effect of resistance (Factor (6)) is negligible below several tens of $\mathrm{k} \Omega$, we exclude this effect as the major mechanism of nonlinearity.

Exceptionally protrusive bundles in the as-prepared cathodes can enhance the electric field. At $2-3 \mathrm{~V} / \mu \mathrm{m}$ in the first run, a higher field enhancement switches on (Fig. 3(b), red). It is difficult to identify the mechanism from the present study, however the effective field at very local protrusions in the first run is variable by field-induced motions of bundles (Factor (3)). Possibly local protrusive emitters in the as-prepared samples rise up by the applied electric field. This finding coincides with the results that the difference in $\beta$ values below and above $3.0 \mathrm{~V} / \mu \mathrm{m}$ for Samples A and B, for which their stems are buried in the forest, is larger than that below and above $2.4 \mathrm{~V} / \mu \mathrm{m}$ for Sample C. Protrusive SWNTs causing giant field enhancement are sublimated, subsequently emission sites will be renewed. It is believed that the total achieved current of ca. $0.5 \mathrm{~mA}$ in the first run is divided into a small number of emission sites induces evaporation of a SWNT (Factor (2)). Finally the sites, which are subjected to comparable enhanced fields, increase. Here Factor (1), adsorbate-enhanced FE, should 
also be noted however FE evaluation after atmospheric exposure and subsequent evacuation indicated the effect of initial protrusion in as-prepared samples is more significant for the first measuring runs than the effect of atmospheric adsorbates.

In the subsequent measuring runs for Sample $\mathrm{C}$, the $E_{\mathrm{to}}, J_{4.0}$ and $\beta$ values (Table II; line 6) are slightly worse than those for Samples A and B (Table II; lines 2 and 4). Figure 4 shows the photographic images of luminescence from the rear surface of the anode at 3.3, 4.1 and $4.8 \mathrm{~V} / \mu \mathrm{m}$ (pulse mode) obtained for Samples A, B and C. Highly localized luminescence observed for Samples A and B (Figs. 4(a) and 4(b)) is caused by the limited number of the emission sites; field enhancement occurs only at the tips of local protrusive bundles but not at the top-surface of VA-SWNTs due to field screening effect. ${ }^{26)}$ Luminescent spots are more widely spread for Sample C than the others. The larger number of luminescent spots for Sample C than Samples A and B corresponds to the larger number of protrusions. However in order to describe screening effect multilevel consideration is necessary. Highly localized emission sites in Samples A and $\mathrm{B}$, which have higher $\beta$ than that of Sample $\mathrm{C}$, are more "screening-free" than the sites in Sample C. The fact that screening effect is still observed in Sample C agrees with the emitter morphology observed by SEM (Fig. 1(c)), which induces the screening effect (inter-bundle distance $<2 \times$ bundle height). ${ }^{26)}$ 
Strictly speaking the F-N relationships are not perfectly linear in the subsequent runs for Samples A and B (Fig. 3(b), blue). Inflection points at around $3 \mathrm{~V} / \mu \mathrm{m}$ are shown by an arrow in Fig. 3(b). Field emission characteristics transform into the "large field enhancement" state with a smaller slope at around $3 \mathrm{~V} / \mu \mathrm{m}$. In the present case, it is believed that a local FE and a local large current induce non-linear F-N relationships. In order to reveal the mechanisms, detail studies for Factors (1) - (5) causing non-linear F-N relationships are necessary.

Field emission properties are determined from (I) primary structure (SWNT, DWNT, ..., MWNT), (II) secondary structure (bundle shape; height, diameter) and (III) tertiary structure (emitter spacing). The major morphological difference between the top surfaces of VA-SWNTs and CNT-grass is therefore tertiary structure.

\subsection{Effect of substrate texturing}

\subsubsection{Characterization of CNTs}

We controlled the secondary (bundle shape) and tertiary (emitter spacing) structures through texturing of substrates as described in $\S 2$. Figure 5 shows SEM micrographs of VA-CNTs and CNT-grass prepared on the textured $\mathrm{Co} / \mathrm{Al}_{2} \mathrm{O}_{3} / \mathrm{Si}$ substrates (Samples D and E). These CNTs have unique structures. Emission sites may 
be CNTs at the apexes of tilted VA-CNT films in Sample D (Fig. 5(a)) and entangled or free-standing bundles at the tips of Si pyramids in Sample E (Fig. 5(b)). In Samples D and $\mathrm{E}$, the number density of the pyramids is approximately $4 \times 10^{5} / \mathrm{cm}^{2}$.

Figure 6 shows representative Raman spectra recorded for Samples D and E. The presence of SWNTs in Sample D is supported by the appearance of RBMs in the low-wavenumber region (Fig. 6(a)). Sample E shows an intense peak at around 520 $\mathrm{cm}^{-1}$ originating from the Si-Si lattice vibration of the Si substrate (Fig. 6(b)). A peak at around $300 \mathrm{~cm}^{-1}$ and another intense peak at around $980 \mathrm{~cm}^{-1}$ detected for Sample E are assigned to background scattering from the Si substrate. Major RBMs detected for Samples A-C (Fig. 2) and a specific band featuring VA-SWNTs at around $180 \mathrm{~cm}^{-1}(\boldsymbol{\nabla})$ are also found for Sample D (Fig. 6(a)). The presence of RBMs is not obvious for Sample E due to the intense background signal at the low wavenumber region (Fig. 6(b)). However, a large G/D-ratio (=21) and a sharp band shape of the G-band support the existence of SWNTs.

\subsubsection{Field emission properties of SWNTs prepared on textured substrates}

In this section, we discuss effects of secondary and tertiary structures on FE properties. Figure 7 shows the $J-E$ curves and the F-N plots obtained from the first (red) 
and third (blue) runs for Samples D and E. Figure 8 shows the photographic images of luminescence from the rear surface of the anode at 3.3, 4.1 and $4.8 \mathrm{~V} / \mu \mathrm{m}$ (pulse mode) for these samples. The FE properties are listed in Table II. Initial protrusions of bundles in the as-grown samples cause giant field enhancement during the first run. Such exceptional protrusions may stretch with increasing applied field and finally evaporate. Compared to for Samples A-C (without texturing), significantly improved FE properties are revealed for Samples D and E in the subsequent runs (Figs. 7, 8 and Table II). For the textured Sample, we exclude the possibility of a lowering of $\phi$ originating from amorphous carbon $(\phi=1.5 \mathrm{eV})^{27)}$, which can be formed on the tips of pyramids by current-induced evaporation. To test this assumption, field emission properties of the textured Si itself $(\phi=4.15 \mathrm{eV})^{28)}$ and an amorphous carbon film $(5 \mathrm{~nm})$ deposited on a textured Si substrate were evaluated and no emission current was detected from either samples up to $5.3 \mathrm{~V} / \mu \mathrm{m}$.

In Sample D, protrusive emission sites are located at the edges of VA-SWNTs on the pyramids (as indicated by arrows in Fig. 5(a), right) since a VA-SWNT film only has small number of protrusions at the top surface (§3.2.2). A number of straggly SWNTs at the edges of the film enhance the applied electric field during the subsequent runs. Moreover in the case that a certain emitter breaks the next emitter becomes active due to 
the high stacking density of aligned SWNTs. As shown in Fig. 8(a), luminescence is observed over the whole area. Lowering of field-screening and an extremely high number of protrusions induce a stable and large area field emission. The inter-pyramid spacing is $10-20 \mu \mathrm{m}$, therefore the screening effect is reduced. Pyramid tips with protrusive bundles selectively become active as emission sites.

Single-bundle emitters with diameters of ca. $10 \mathrm{~nm}$ (Fig. 5(b)) and inter-bundle spacing of $10-20 \mu \mathrm{m}$ in Sample E show the lowest $E_{\text {to }}$, largest $J_{4.0}$ (Table II) and the largest number of luminescent spots (Fig. 8(b)). However the $\beta$ value for the subsequent repetitive runs is still comparable with that for Sample D. Single-bundle emitters entangle or free-stand at the tips of Si pyramids (Fig. 5(b)). These bundles are shorter than straggled bundles at the edges of the VA-SWNT film in Sample D (Fig. 5(a)). Screening-free but short bundles in Sample E settles the $\beta$ as large as that for Sample D. On the other hand, luminescence image at $3.3 \mathrm{~V} / \mu \mathrm{m}$ in Fig. 8(b) shows how the emission sites disperse in comparison with other samples. Assuming that the number density of the pyramids in Sample E is approximately $4 \times 10^{5} / \mathrm{cm}^{2}$ (based on SEM observation) and field enhancement selectively occurs at the tips of pyramids at $4 \mathrm{~V} / \mu \mathrm{m}$, the current density of ca. $1 \mathrm{~mA} / \mathrm{cm}^{2}$ corresponds to $2.5 \mathrm{nA}$ per pyramid. This gives us a rough estimate for a tolerable driving current per micro-cathode. Several nA per 
micro-cathode is a possible design for SWNT-FEDs.

Figure 9 shows linear regressions for the F-N plots obtained from the repetitive measurements (3rd - 8th runs) for Samples A and E. It is clear that the field enhancement behavior obtained for Sample E is much more stable in comparison with Sample A. These results indicate that a well separated tertiary structure and a large tip curvature of single-bundle protrusions, which fulfill (1) low driving voltage, (2) large area FE and therefore (3) long life-time, can be prepared though ACCVD by controlling surface morphologies. In addition, up to now it is revealed that a reaction time of $10 \mathrm{~s}$ is sufficient to prepare SWNT-emitters under ACCVD conditions used in this work. Consequently morphologically controlled SWNTs prepared through CVD methods have potential performances for FED applications.

\section{Conclusions}

SWNT-emitters were prepared on $\mathrm{Co} / \mathrm{Al}_{2} \mathrm{O}_{3}(\mathrm{Al}) / \mathrm{Si}$ substrates through ACCVD, which realizes a reaction time of $10 \mathrm{~s}$ to grow a $4 \mu \mathrm{m}$-thick SWNT film. Field emission properties of the obtained SWNTs were evaluated under the diode-type configuration. For a textured Si cathode with SWNT-emitters on Si pyramids, the turn-on electric field to extract a current density of $1 \mu \mathrm{A} / \mathrm{cm}^{2}$ was $2.4 \mathrm{~V} / \mu \mathrm{m}$, and a current density of 0.8 
$\mathrm{mA} / \mathrm{cm}^{2}$ was recorded at $4 \mathrm{~V} / \mu \mathrm{m}$. Large area luminescence uniformity $\left(0.5 \mathrm{~cm}^{2}\right)$ was also obtained. The study based on the Fowler-Nordheim model showed that field emission properties of SWNTs are tunable by the morphological control of the top-surface. Protrusion of emitters is crucial and the optimization of number density, protrusion length and inter-protrusion distance is necessary for uniform field emission and increased operating life. Texturing of substrates effects a large and selective field enhancement at specific protrusive emitters. Currently, SWNTs prepared from ethanol via a fast and safe process showed field mission characteristics suitable for electron sources. Controllability of SWNT-growth and morphology is advantageous for further study on field emission properties.

\section{Acknowledgement}

We gratefully thank Mr. Kageyasu Kuroki and Mr. Toshio Ohsawa for technical supports and Mr. Takao Kishino for phosphor-printing process. The authors sincerely acknowledge the Ministry of Education, Culture, Sports, Science and Technology (MEXT), Japan for granting a partial financial support: a Grant-in-Aid for Young Scientists (A), 1868602, 2006. 


\section{References}

1) A. G. Rinzler, J. H. Hafner, P. Nikolaev, L. Lou, S. G. Kim, D. Tománek, P. Nordlander, D. T. Colbert, and R. E. Smalley: Science 269 (1995) 1550.

2) J. E. Jung, Y. W. Jin, J. H. Choi, Y. J. Park, T. Y. Ko, D. S. Chung, J. W. Kim, J. E. Jang, S. N. Cha, W. K. Yi, S. H. Cho, M. J. Yoon, C. G. Lee, J. H. You, N. S. Lee, J. B. Yoo, and J. M. Kim: Physica B 323 (2002) 71.

3) B. F. Coll, K. A. Dean, E. Howard, S. V. Johnson, M. R. Johnson, H. Li, D. C. Jordan, L. H. Tisinger, M. Hupp, S. M. Smith, S. R. Young, J. Backer, D. Weston, W. J. Dauksher, Y. Wei, and J. E. Jaskie: EURODISPLAY '05, 2005, p. 144.

4) S. Itoh, M. Tanaka, and T. Tonegawa: J. Vac. Sci. Technol. B 22 (2004) 1362.

5) S. Maruyama, R. Kojima, Y. Miyauchi, S. Chiashi, and M. Kohno: Chem. Phys. Lett. 360 (2002) 229.

6) Y. Murakami, S. Chiashi, Y. Miyauchi, M. Hu, M. Ogura, T. Okubo, and S. Maruyama: Chem. Phys. Lett. 385 (2004) 298.

7) M. Tamura, Y. Kemmochi, Y. Murakami, N. Chino, M. Ogura, S. P. Naik, M. Takai, Y. Tsuji, S. Maruyama, and T. Okubo: Appl. Phys. A 84 (2006) 247.

8) L. Zhang, L. Balzano, and D. E. Resasco: J. Phys. Chem. B 109 (2005) 14375.

9) S. Noda, Y. Tsuji, Y. Murakami, and S. Maruyama: Appl. Phys. Lett. 86 (2005) 
173106

10) S. Noda, H. Sugime, T. Ohsawa, Y. Tsuji, S. Chiashi, Y. Murakami, and S. Maruyama: Carbon 44 (2006) 1414.

11) M. Sveningsson, R.-E. Morjan, O.A. Nerushev, Y. Sato, J. Bäckström, E.E.B. Campbell, and F. Rohmund: Appl. Phys. A 73 (2001) 409.

12) S. Noda, K. Hasegawa, H. Sugime, K. Kakehi, Z. Zhang, S. Maruyama, and Y. Yamaguchi: Jpn. J. Appl. Phys. 46 (2007) L399.

13) L. Zhang, Y. Tan, and D. E. Resasco: Chem. Phys. Lett. 422 (2006) 198.

14) Y. Murakami, S. Chiashi, E. Einarsson, and S. Maruyama: Phys. Rev. B 71 (2005) 085403.

15) K. A. Dean and B. R. Chalamala: Appl. Phys. Lett. 76 (2000) 375.

16) Y. C. Choi, Y. M. Shin, D. J. Bae, S. C. Lim, Y. H. Lee, and B. S. Lee: Diamond Relat. Mater. 10 (2001) 1457.

17) J.-M. Bonard, C. Klinke, K. A. Dean, and B. F. Coll: Phys. Rev. B 67 (2003) 115406.

18) Y. Saito, K. Seko, and J. Kinoshita: Diamond Relat. Mater. 14 (2005) 1843.

19) Y. Wei, C. Xie, K. A. Dean, and B. F. Coll: Appl. Phys. Lett. 79 (2001) 4527.

20) C. Jin, J. Wang, M. Wang, J. Su, L.-M. Peng: Carbon 43 (2005) 1026. 
21) H. Sato, K. Hata, H. Miyake, K. Hiramatsu, and Y. Saito: J. Vac. Sci. Technol. B 23 (2005) 754.

22) D. L. Carroll, P. Redlich, P. M. Ajayan, J. C. Charlier, X. Blase, A. De Vita, and R. Car: Phys. Rev. Lett. 78 (1997) 2811.

23) J.-M. Bonard, J.-P. Salvetat, T. Stöckli, W. A. de Heer, L. Forró, and A. Châtelain: Appl. Phys. Lett. 73 (1998) 918.

24) W. B. Choi, Y. H. Lee, N. S. Lee, J. H. Kang, S. H. Park, H. Y. Kim, D. S. Chung, S. M. Lee, S. M. Lee, S. Y. Chung, and J. M. Kim: Jpn. J. Appl. Phys. 39 (2000) 2560.

25) N. S. Xu, Y. Chen, S. Z. Deng, J. Chen, X. C. Ma, and E. G. Wang: J . Phys. D: Appl. Phys. 34 (2001) 1597.

26) N. S. Xu and S. E. Huq: Mater. Sci. Eng. R 48 (2005) 47.

27) V. M. Anishchik, V. V. Uglov, A. K. Kuleshov, A. R. Filipp, D. P. Rusalsky, M. V. Astashynskaya, M. P. Samtsov, T. A. Kuznetsova, F. Thiery, and Y. Pauleau: Thin Solid Films 482 (2005) 248.

28) C. Li, G. Fang, S. Sheng, Z. Chen, J. Wang, S. Ma, and X. Zhao: Physica E 30 (2005) 169. 
Captions for figures

Fig. 1. SEM micrographs of $(\mathrm{a}, \mathrm{b}) \mathrm{VA}-\mathrm{CNTs}$ on the $\mathrm{Co} / \mathrm{Al}_{2} \mathrm{O}_{3} / \mathrm{Si}$ (Sample A) and $\mathrm{Co} / \mathrm{Al} / \mathrm{Si}$ (Sample B) substrates and (c) CNT-grass on the Co/Al/Si substrate (Sample C). Enlarged image of the top surface of Sample A is shown in (a)-right. Protrusive bundles in Sample C are indicated by arrows (c).

Fig. 2. Raman spectra of (a, b) VA-CNTs on the $\mathrm{Co} / \mathrm{Al}_{2} \mathrm{O}_{3} / \mathrm{Si}$ (Sample A) and $\mathrm{Co} / \mathrm{Al} / \mathrm{Si}$ (Sample B) substrates and (c) CNT-grass on the Co/Al/Si substrate (Sample C). Enlarged spectra of the low wavenumber region are indicated in the insets. Major RBMs are marked by triangles and auxiliary lines: $(\boldsymbol{\nabla})$ vertically aligned SWNTs and $(\nabla)$ others.

Fig. 3. (a) $J-E$ curves and (b) F-N plots obtained from the first (red) and the third (blue) measuring runs under the dc-voltage sweep mode for Samples A $(\circ), B(\bullet)$ and $C(\triangle)$. F-N plots for the first runs are composed of two linear relationships with the slopes $\mathrm{s}_{1}(<$ $3 \mu \mathrm{m})$ and $\mathrm{s}_{2}(>3 \mu \mathrm{m})$. Changes of the slopes observed for Samples A and B at around 3 $\mathrm{V} / \mu \mathrm{m}$ during the third run are indicated by an arrow. 
Fig. 4. Pictures of luminescence from the rear surface of the anode at 3.3, 4.1 and 4.8 $\mathrm{V} / \mu \mathrm{m}$ under the pulse driving mode $(5 \mathrm{~ms}, 1 / 2$-duty) and cross-sectional SEM micrographs; (a) Sample A, (b) Sample B and (c) Sample C.

Fig. 5. SEM micrographs of (a) VA-CNTs on Sample D (left: top view, right: cross sectional view) and (b) CNT-grass on Sample E (left: entangled bundle, right: vertically standing bundle) prepared on the textured $\mathrm{Co} / \mathrm{Al}_{2} \mathrm{O}_{3} / \mathrm{Si}$ substrates. Protrusions are indicated by arrows. Inset in (b) is an enlarged image of the bundle.

Fig. 6. Raman spectra of (a) VA-CNTs (Sample D) and (b) CNT-grass (Sample E) prepared on the textured $\mathrm{Co} / \mathrm{Al}_{2} \mathrm{O}_{3} / \mathrm{Si}$ substrates. Enlarged spectra in the low wavenumber region are indicated in the insets. Major RBMs are marked by triangles and auxiliary lines: $(\boldsymbol{\nabla})$ vertically aligned SWNTs and $(\nabla)$ others.

Fig. 7. (a) $J-E$ curves and (b) F-N plots obtained from the first (red) and the third (blue) measuring runs under the dc-voltage sweep mode for Samples D $(\bullet)$ and E (०). F-N plots for the first runs are composed of two linear relationships with the slopes $s_{1}(<2$ $\mu \mathrm{m})$ and $\mathrm{s}_{2}(>2 \mu \mathrm{m})$. 
Fig. 8. Pictures of luminescence from the rear surface of the anode at 3.3, 4.1 and 4.8 $\mathrm{V} / \mu \mathrm{m}$ under the pulse driving mode $(5 \mathrm{~ms}, 1 / 2$-duty) and cross-sectional SEM micrographs; (a) Sample D and (b) Sample E. The dark part at the upper left of the phosphor screen (b) corresponds to a technically generated texture-free area.

Fig. 9. F-N plots obtained from the third to the eighth measuring runs (red: $3 \mathrm{rd}$, green: 4th, blue: 5th, brown: 6th, pink: 7th, light blue: 8th) under the dc-voltage sweep mode for (a) Sample A and (b) Sample E. 
Tables

Table I. Conditions of ACCVD on Si substrates at the substrate temperature of $785{ }^{\circ} \mathrm{C}$ and ethanol gas pressure of $4 \mathrm{kPa}$.

\begin{tabular}{|c|c|c|c|c|c|c|c|}
\hline \multirow[t]{2}{*}{ Sample } & \multirow{2}{*}{$\begin{array}{c}\text { Morphology } \\
\text { of CNTs }\end{array}$} & \multicolumn{3}{|c|}{ Layer thickness $(\mathrm{nm})^{* 1}$} & \multirow{2}{*}{$\begin{array}{l}\text { Time } \\
(\mathrm{sec})\end{array}$} & \multirow{2}{*}{$\begin{array}{c}\text { CNT film } \\
\text { thickness }(\mu \mathrm{m})\end{array}$} & \multirow{2}{*}{$\begin{array}{l}\text { G/D- } \\
\text { ratios }^{* 5}\end{array}$} \\
\hline & & $\mathrm{Co}^{* 2}$ & $\mathrm{Al}^{* 3}$ & $\mathrm{Al}_{2} \mathrm{O}_{3}{ }^{* 3}$ & & & \\
\hline $\mathrm{A}$ & $\mathrm{VA}^{* 6}$ & 1.2 & - & 10 & 60 & 2.7 & 10 \\
\hline $\mathrm{B}$ & VA & 1.2 & 7 & - & 60 & 6.0 & 6 \\
\hline $\mathrm{C}$ & Grass & 1.2 & - & 10 & 60 & 0.3 & 14 \\
\hline $\mathrm{D}$ & VA on Tex. ${ }^{* 7}$ & 1.2 & - & 10 & 10 & 4.0 & 8 \\
\hline $\mathrm{E}$ & Grass on Tex. & 1.2 & - & 10 & 60 & 0.3 & 21 \\
\hline
\end{tabular}

${ }^{* 1}$ Average thickness on a flat surface. ${ }^{* 2}$ Catalytic layer. ${ }^{* 3}$ Supporting layer. ${ }^{* 4}$ Data obtained from Raman spectroscopy presented below. ${ }^{* 5}$ VA: vertically aligned. ${ }^{* 6}$ Tex.: textured Si substrate. 
Table II. Turn-on electric fields $\left(E_{\mathrm{to}}\right)$, current densities at $4 \mathrm{~V} / \mu \mathrm{m}\left(J_{4.0}\right)$ and field enhancement factors $(\beta)$ obtained for Samples A-E.

\begin{tabular}{|c|c|c|c|c|c|}
\hline Sample & Run & $E_{\mathrm{to}}\left(\mathrm{V} \mu \mathrm{m}^{-1}\right)$ & $J_{4.0}\left(\mathrm{mAcm}^{-2}\right)$ & \multicolumn{2}{|c|}{$\beta \times 10^{-5}\left(\mathrm{~cm}^{-1}\right)$} \\
\hline \multirow{3}{*}{ A } & \multirow{2}{*}{$1 \mathrm{st}$} & \multirow{2}{*}{1.9} & \multirow{2}{*}{0.4} & $<3.0 \mathrm{~V} / \mu \mathrm{m}$ & $>3.0 \mathrm{~V} / \mu \mathrm{m}$ \\
\hline & & & & 2.7 & 10.4 \\
\hline & $3 \mathrm{rd}-$ & 2.9 & 0.2 & \multicolumn{2}{|c|}{1.0} \\
\hline \multirow{3}{*}{ B } & \multirow{2}{*}{$1 \mathrm{st}$} & \multirow{2}{*}{2.7} & \multirow{2}{*}{0.5} & $<3.0 \mathrm{~V} / \mu \mathrm{m}$ & $>3.0 \mathrm{~V} / \mu \mathrm{m}$ \\
\hline & & & & 2.7 & 10.0 \\
\hline & $3 \mathrm{rd}-$ & 2.7 & 0.2 & \multicolumn{2}{|c|}{1.3} \\
\hline \multirow{3}{*}{$\mathrm{C}$} & \multirow{2}{*}{$1 \mathrm{st}$} & \multirow{2}{*}{1.4} & \multirow{2}{*}{0.5} & $<2.5 \mathrm{~V} / \mu \mathrm{m}$ & $>2.5 \mathrm{~V} / \mu \mathrm{m}$ \\
\hline & & & & 4.5 & 7.1 \\
\hline & $3 \mathrm{rd}-$ & 3.1 & 0.1 & \multicolumn{2}{|c|}{0.9} \\
\hline \multirow{3}{*}{$\mathrm{D}$} & \multirow{2}{*}{$1 \mathrm{st}$} & \multirow{2}{*}{1.4} & \multirow{2}{*}{1.0} & $<1.9 \mathrm{~V} / \mu \mathrm{m}$ & $>1.9 \mathrm{~V} / \mu \mathrm{m}$ \\
\hline & & & & 3.5 & 9.1 \\
\hline & $3 r d-$ & 2.4 & 0.6 & \multicolumn{2}{|c|}{1.6} \\
\hline \multirow{3}{*}{$\mathrm{E}$} & \multirow{2}{*}{$1 \mathrm{st}$} & \multirow{2}{*}{1.3} & \multirow{2}{*}{1.2} & \multicolumn{2}{|l|}{$<1.8 \mathrm{~V} / \mu \mathrm{m}$} \\
\hline & & & & 3.2 & 8.6 \\
\hline & $3 r d-$ & 2.4 & 0.8 & \multicolumn{2}{|c|}{1.4} \\
\hline
\end{tabular}




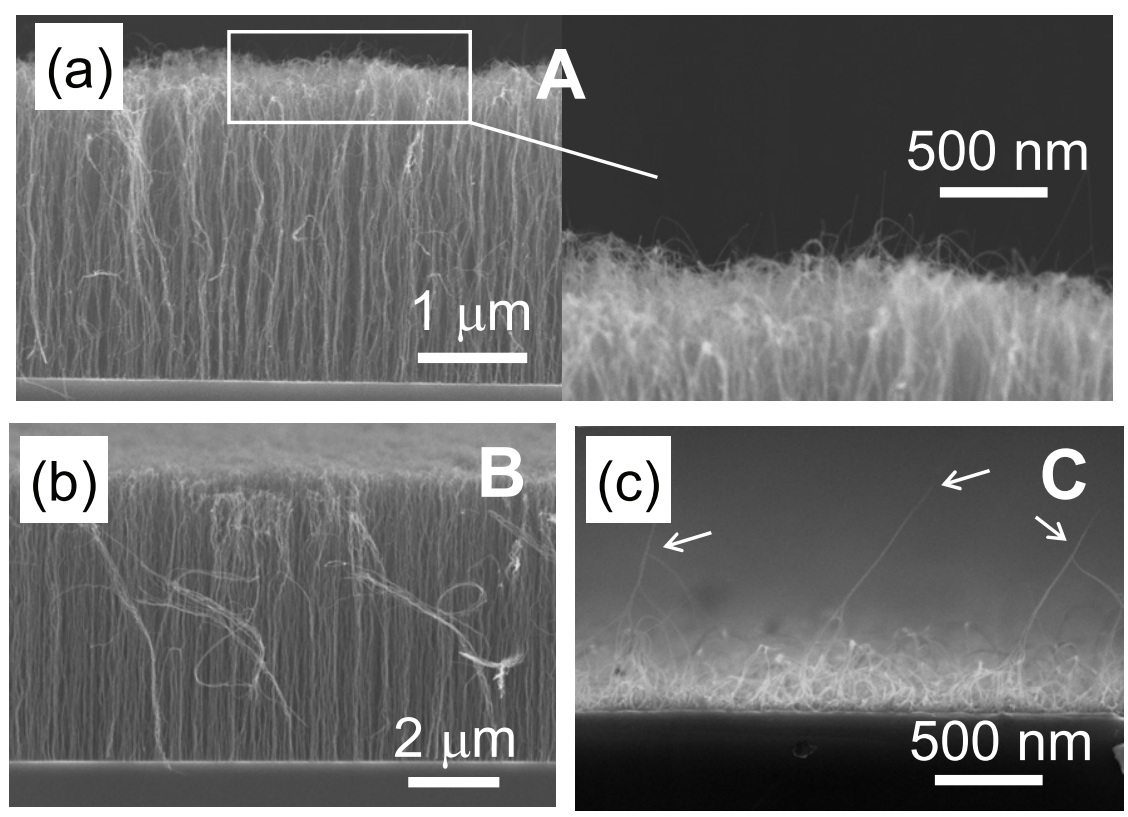

Fig. 1 


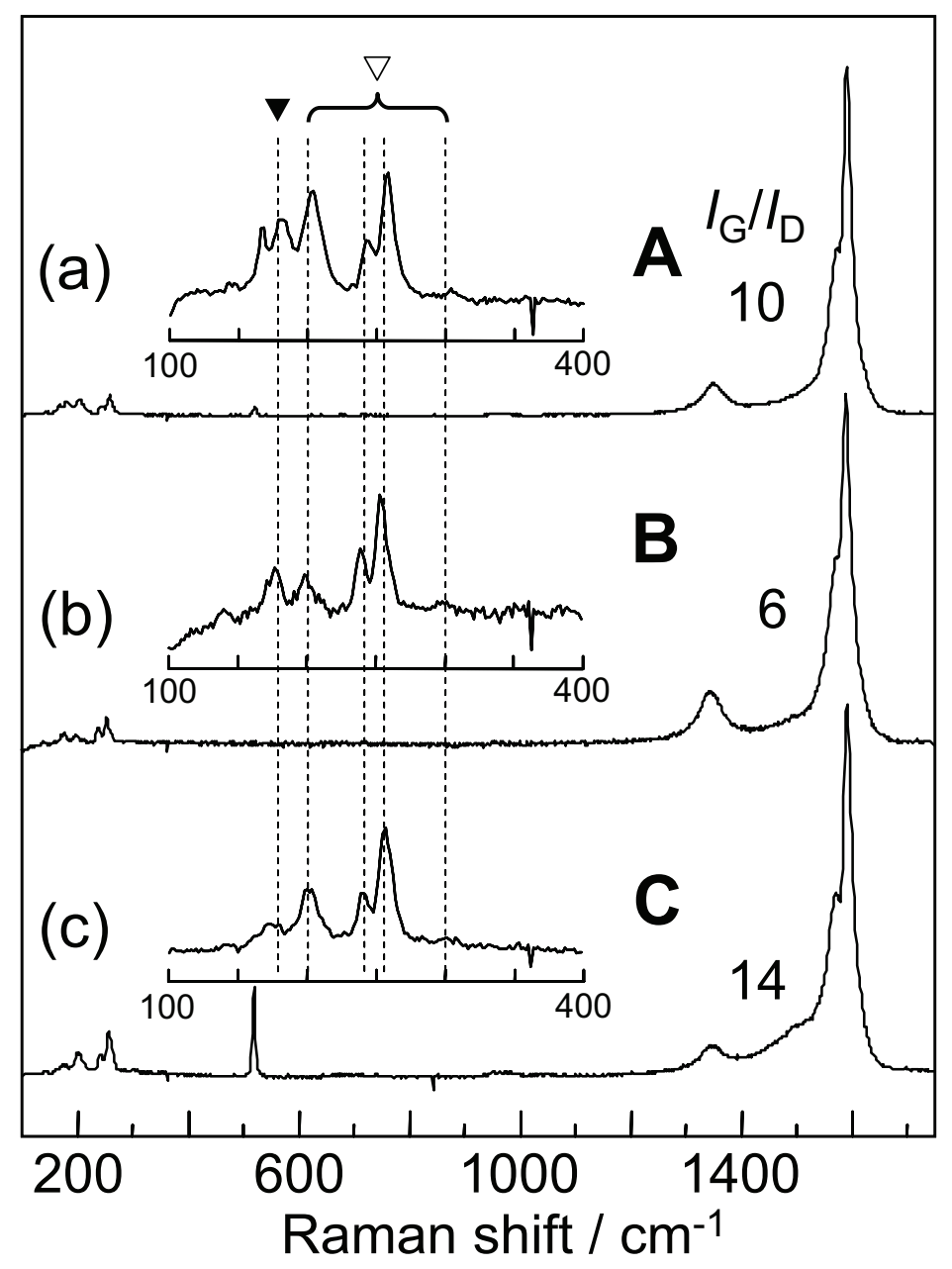

Fig. 2 


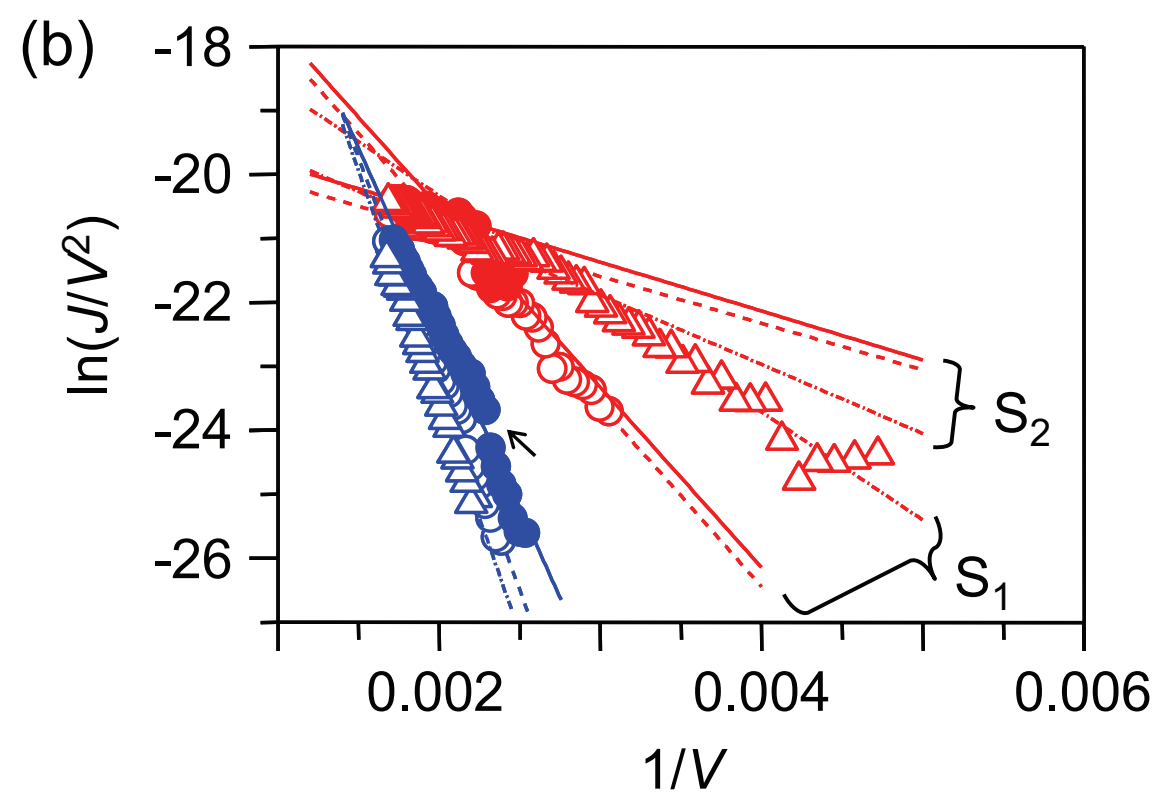

(a)

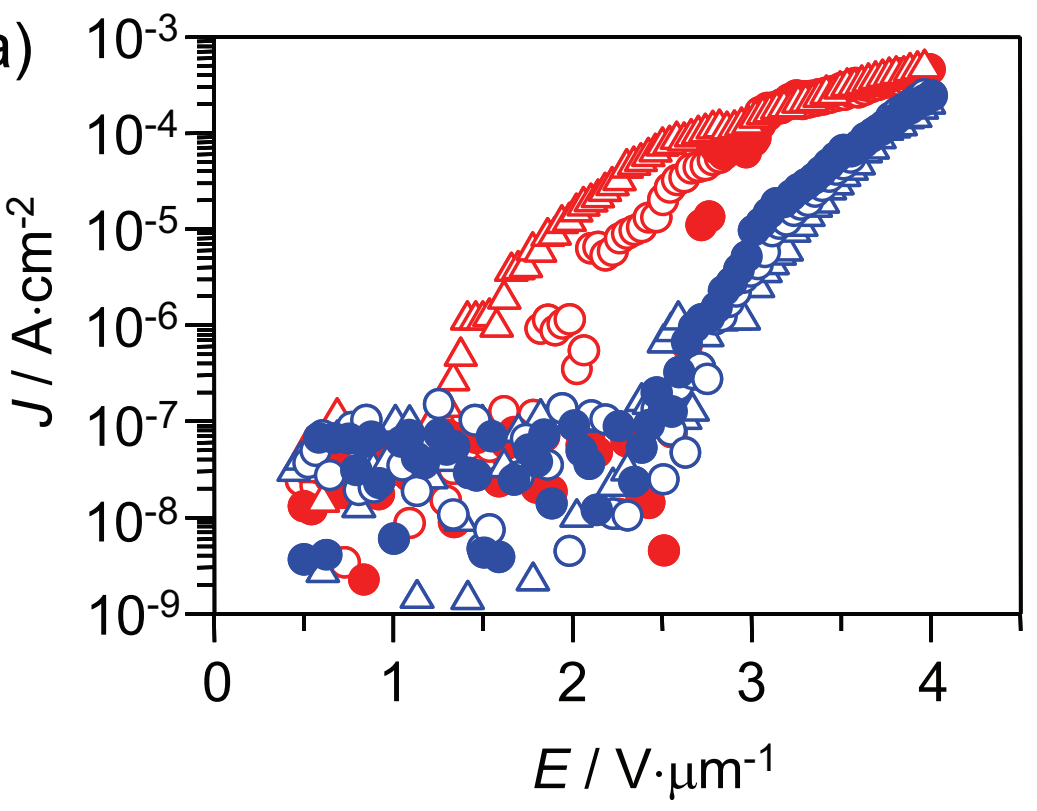

Fig. 3 (We prefer color print) 


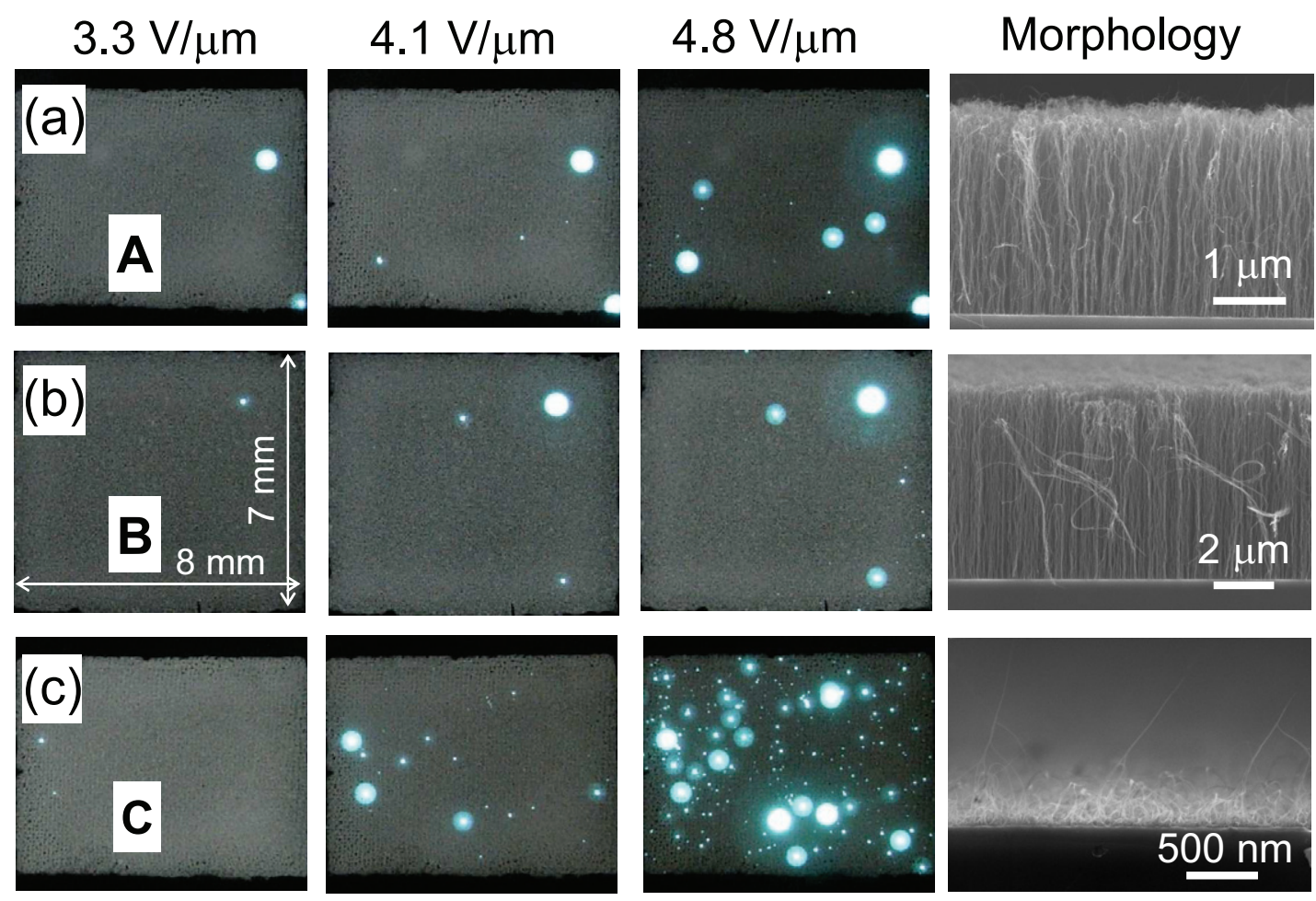

Fig. 4 (We prefer color print) 

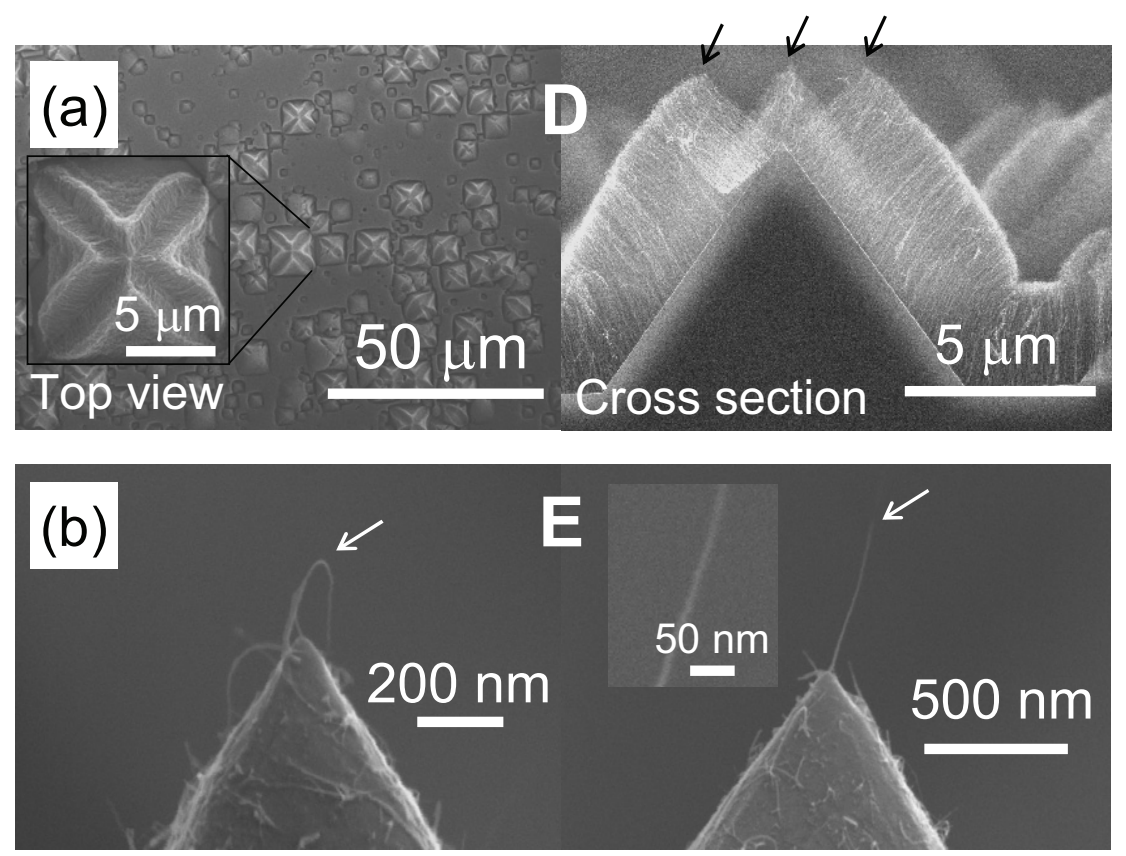

Fig. 5 


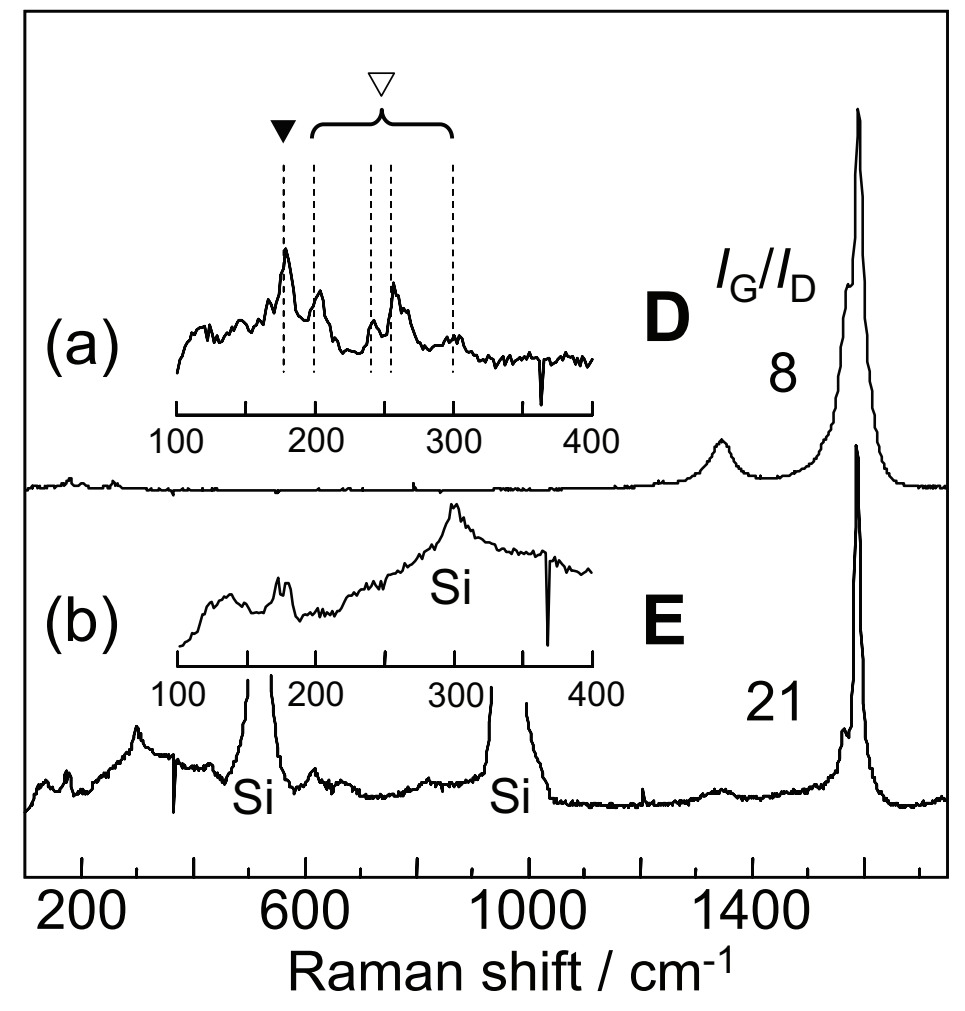

Fig. 6 

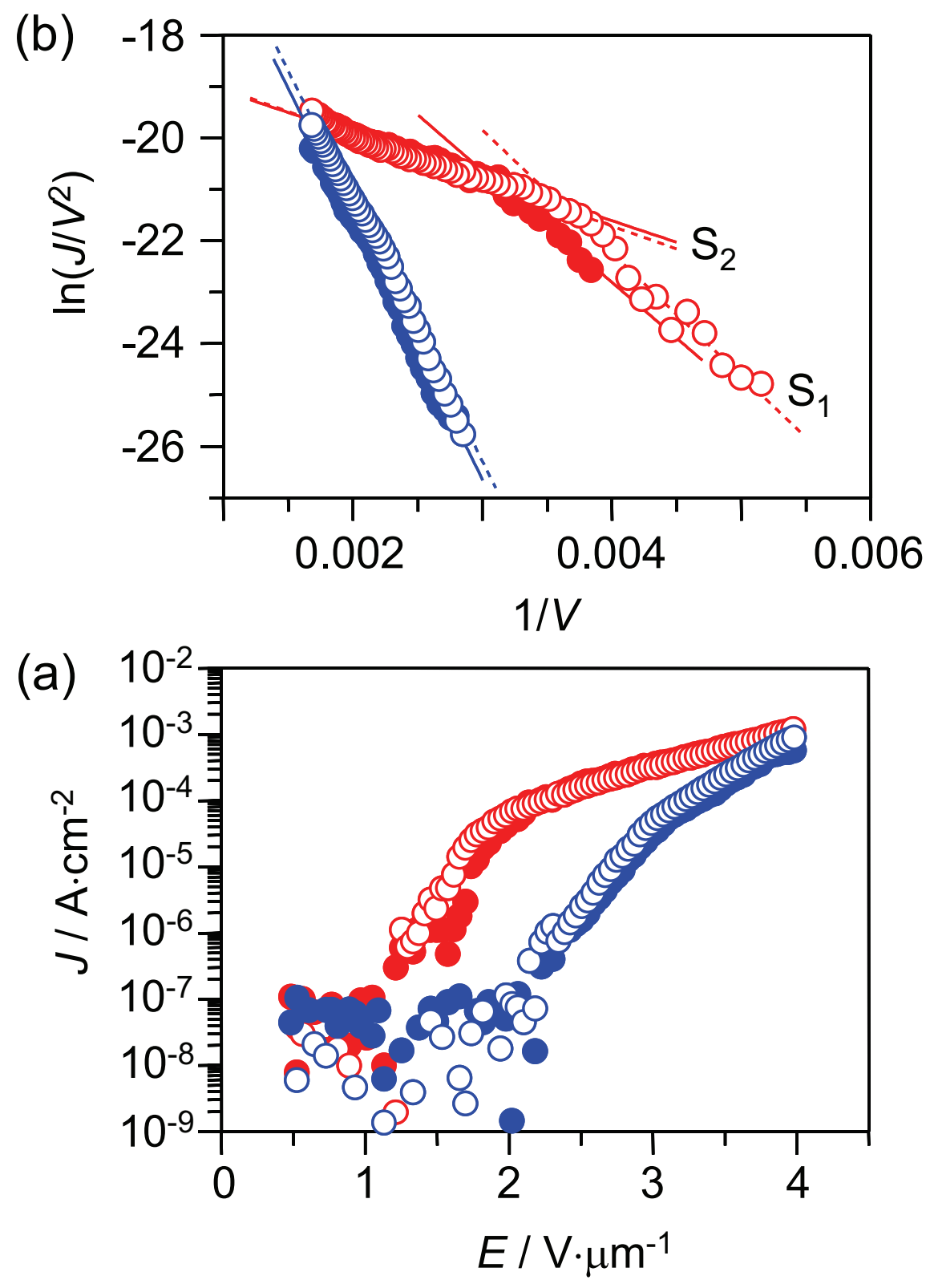

Fig. 7 (We prefer color print) 


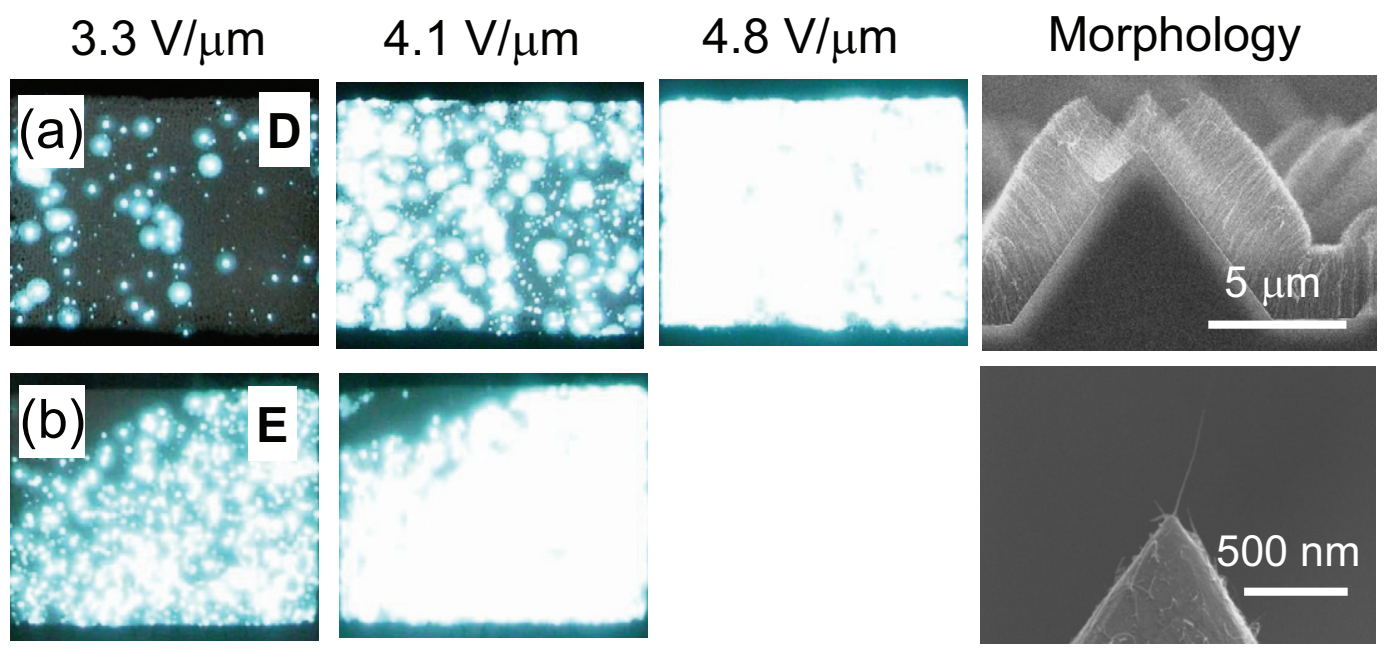

Fig. 8 (We prefer color print) 

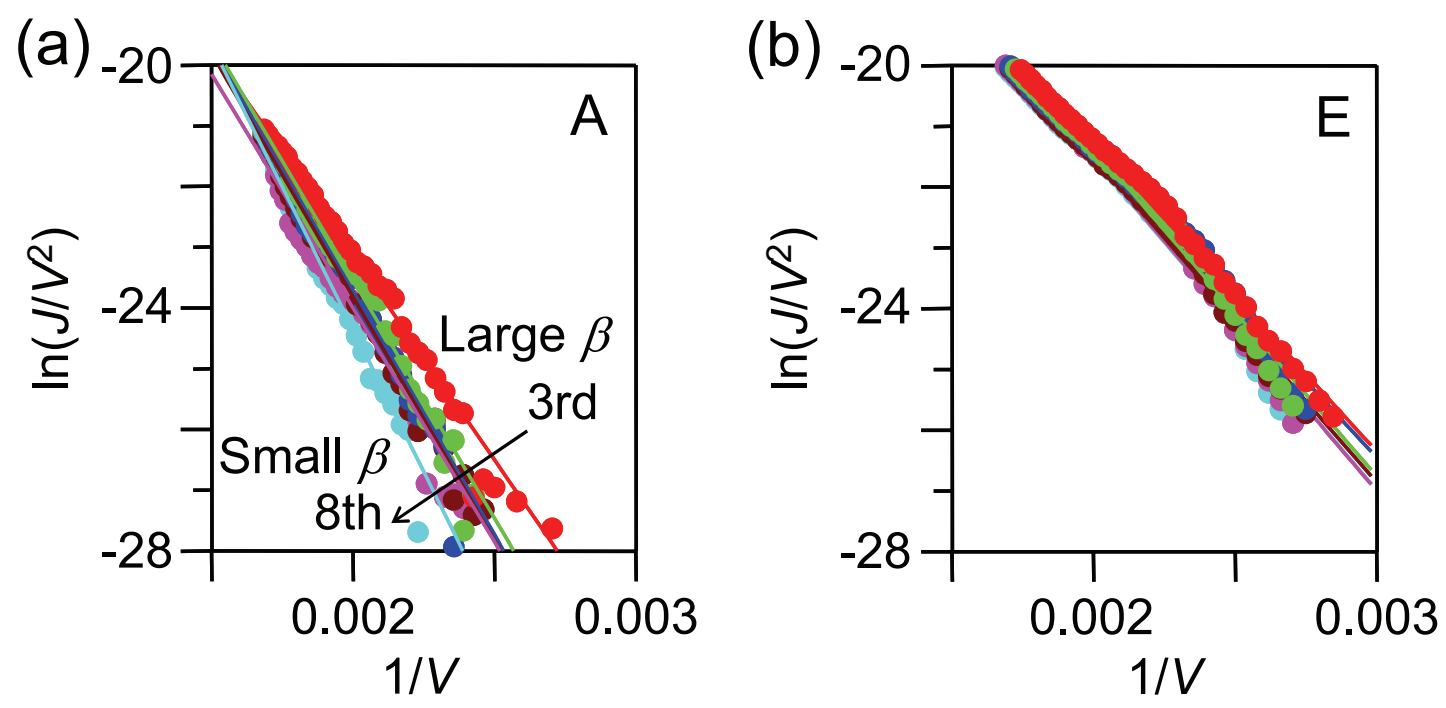

Fig. 9 (We prefer color print) 